\title{
Making virtual learning interactive and meaningful:
} Implications of constructivism for adult students

\author{
Khanal, Peshal $\square$ \\ Central Department of Education, Tribhuvan University, Nepal (peshalk@gmail.com)
}

Accepted: 13 October 2013

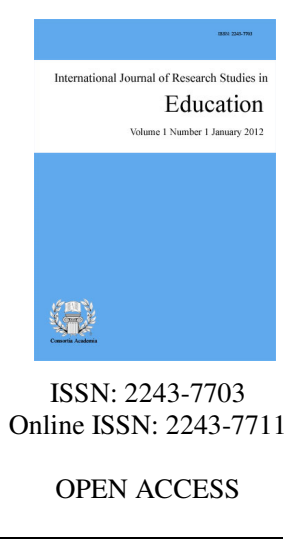

\begin{abstract}
There has been a growing trend of online education in higher education, with its ever-increasing popularity among adult learners in particular. However, due to the lack of real-life, interactive environment in web-based settings, the problem persists as to how the learning becomes effective, interactive and meaningful. This article attempts to address this issue by exploring the implications of constructivism for interactive online learning, with a particular focus on the characteristics and needs of adult learners. Following a brief review of scholarships surrounding the issue of constructivism, adult learning and online learning, this article explores and discusses five implications of constructivism for online adult learning program - interactive learning, experiential learning, self-directed learning, collaborative learning and authentic learning.
\end{abstract}

Keywords: constructivism; adult learning; online learning; virtual learning; collaborative learning 


\section{Making virtual learning interactive and meaningful: Implications of constructivism for adult students}

\section{Introduction}

Online education - that is education delivered via the Internet - has been growing in popularity, particularly in higher education since mid-1990s with the aim of fulfilling the educational need of non-traditional students (Harmon and Jones, 1999). However, most of the online courses are designed and offered overlooking the difference in learning needs and strategies between the traditional age-group learners and adult learners (Brookfield, 1995). Many researchers (e.g. Knowles, Holton and Swanson, 1998; Huang, 2002) have suggested that adults have special characteristics, experiences and learning requirements compared to other young children and adolescents. Likewise, adults have different learning styles and approaches, with particular factors to influence and motivate them for learning. According to Knowles (1980), adult learners are rather autonomous and self-directed, who have a wealth of life experiences and knowledge. Moreover, they are goal-oriented and see always reason for learning something. Therefore, online educators need to identify the age category of learners and assess their learning characteristics and needs prior to designing the learning program.

In most countries, the adult participation in distance education program is continually growing (Ke \& Xie, 2009). However, the problem persists as to the nature of adult learning program and the pedagogical intervention for maximizing the effective and meaningful learning at later ages. In this context, drawing upon constructivism this paper attempts to explore the ways to enhance adult learning in a distance learning environment and the ways the learning becomes effective, interactive and meaningful. It is argued that the traditional distance education (e.g. program via radio, television, correspondence) fails to provide learners with an interactive environment and thus imparting meaningful learning through shared learning activities in traditional system is less likely. With the introduction of the Internet in distance learning sector, several possibilities of interactive teaching are available in the virtual learning environment. However, while employing the web-based interaction as a form of pedagogical strategy, many issues of effective and meaningful leaning are to be considered. In this article I attempt to explore the constructivists' notion of learning that provides insight into the Internet-based pedagogy and learning. In doing so, I divide the remaining paper into three core sections. In the first section, I review the underlying concepts surrounding constructivism, adult learning and online technology in order to provide a theoretical background and context of the study. In the middle section, I explore certain notions of constructivism relevant to online learning. The final section discusses the implications of constructivism for adult learning in an online environment.

\section{Constructivism}

Constructivism is an umbrella term that represents a group of theories. However, a major thrust of these theories is that the meaningful learning occurs as a result of students' active engagement in a shared learning environment. Constructivism is a philosophy of learning based on the premise that knowledge is constructed by the individual through his or her interactions with the environment. It has its roots in cognitive psychology, which holds that individuals gradually build their own understanding of the world through experience, maturation, and interaction with the environment. Thus, from the constructivist viewpoint, the learner is an active processor of information. The fundamental assumption of constructivism underscores the dynamic interactions between the cognitive and social dimensions of learning (e.g. Resnick \& Collins, 1996), and accordingly, constructivism is subsumed under two broad categories - cognitive constructivism and social constructivism. Cognitive Constructivism (Piaget, 1977) combines aspects of both cognitive theory and constructivism and argues that learning is a process of accommodation, assimilation and equilibrium. Thus, where knowledge is highly interconnected and complex, many different representations of content are necessary to create deep 
Making virtual learning interactive and meaningful: Implications of constructivism for adult students

learning. In relation to online education, the Internet can provide a technological backbone for creating a highly complex interconnected information environment (primarily via hypertext links) where knowledge can be acquired. However, how the engagement of a learner's interest takes place in such a complex information environment is not addressed by Piaget's theory-mainly because it was developed long before the Internet became a serious facilitator in education.

Social Constructivism goes a step further in the theory of learning. This theory, according to Vygotsky (1978), argues that learning is not purely an internal process, nor is it passive, but that culture and context are highly important in forming understanding and hence the beginnings of deep learning. Thus, learning is seen as the development of higher level psychological processes occurring first on an interpersonal level through social interaction and then being internalized. Vygotsky also introduced the concept of Zone of Proximal Development (ZPD) which he defines as 'the distance between the actual development level determined by independent problem solving and the level of potential development as determined by problem solving under adult guidance or in collaboration with more capable peers' (p. 89). He further contends that the ZDP is an area where maximum learning takes place. In order to maximize the learning within ZDP, a supporting structure to students' learning is essential through the process of scaffolding.

Constructivist's approach to scaffolding emphasizes the interaction-based support system by providing students with maximum supportive environment for communication, participation and meaningful engagement in activities through questioning, cueing, prompting, coaching, modeling, and instruction (Bryceson, 2007). Social constructivists brought forth the idea that participation in social interaction and symbolically mediated thought facilitated by language and dialogue, dependent on socio-historical nature of a society, are important for individual learning. While this form of supportive system in traditional face-to-face classrooms has been clearly acknowledged, less has been discussed in virtual learning settings (McLoughlin, 2002).

There are several implications of constructivism for active learning. The major implications of constructivism for a learning environment include using curricula customized to the students' prior knowledge, tailoring of teaching strategies to student backgrounds and responses, and employing open-ended questions that promote extensive dialogue among learners (Rovai, 2004). Questioning, therefore, becomes the major means by which students are helped to construct meaning. However, according to Brooks and Brooks (1993), the constructivist approach is more than just activities. In not treating students as passive learners, more respect is shown to students as learners and as human beings. It is very important for the instructor to be aware of initial student misunderstandings to provide the kinds of experiences that will allow the student to learn. It is this pragmatic view of constructivism that provides the philosophical basis for this article.

There are certain implications of constructivism for online education. Rovai (2004) mentioned Jonassen's (1994) suggestions that constructivism should be applied to distance education and proposed a constructivist design model for online learning that included the following guidelines:

Focus on knowledge construction, not reproduction... Present authentic tasks... [that] provide real world case-based learning environments,. . .Foster reflective practice, and enable context and content dependent knowledge construction,...Support collaborative construction of knowledge through social negotiation, not competition among learners for recognition (p. 35).

Huang (2002) summarized seven issues of constructivism for online educators. The first is the issue of humanity and the possibility of learner's isolation. Since online education is based on the individual learning and online interaction, it loses some humanity and isolates learner from the social group. The second is the problem associated with the quality and authenticity of the learning. In online environment, the Internet provides only the information and learning takes place beyond the instructor's scope; therefore, it is difficult to ensure the quality and authenticity of learning by the learners themselves. The third implication is the changing role of educator from instructor to consultant, guide and resource provider. The fourth is the controversy of pre-authentication. Pre-authentication - the attempt to make learning materials and environments correspond to the real world prior 
to the learner's interaction with them (Petraglia, 1998, p. 53) - is likely to be controversial in online setting even if the online courses are designed by hypertext or hypermedia. The fifth issue is the problem associated with the evaluation of learners' achievement. For constructivist like Dewey, experience is always the starting point of an educational process, not a result (Knowles et al., 1998) and the "learning to learn" of adult learning theory also focuses on the learning process, not only the result. Therefore, constructivists view measurement and evaluation of learning outcomes as problematic component of the instruction. The next concern is the individuals' difference in learning choice and the possibility to customize curriculum and learning materials to their learning styles, their cultural backgrounds, their educational interests and their academic goals.

The final implication of constructivism for online learning is the conflict of collaborative learning with individual difference, particularly for adult learners. It is because that collaborative learning stresses student to work together cooperating and collaborating the ideas each other but by principle adult learners are more self-directive and characterized by taking control on their learning processes and objectives. Therefore, collaborative learning, one key aspects of constructivism, remains challenging for adult learning. Considering all of these implications, and relating them to the adult learning theory in the next section, I would provide the implications of constructivism for adult learners in online setting.

\section{Adult Learning}

Malcolm Knowles proposed a theory of adult learning, pedagogy for adults, called andragogy (Knowles, Holton III, \& Swanson, 1998). According to this theory, there are six principles of adult learning. The first principle is the learner's need to know: "how learning will be conducted, what learning will occur, and why learning is important" (Knowles et al., 1998, p. 133). Second, self-directed learning is the ability of taking control of the techniques and of the purposes of learning. Then, prior experience of the learner impacts learning in creating individual differences, providing rich resources, creating biases and providing adults' self-identity. The fourth principle is readiness to learn. Adults become ready to learn when their life situations create a need to learn. The fifth principle is orientation to learning.

In general, adults prefer a problem solving orientation in learning. In particular, they can earn best when knowledge is presented in real-life context. The sixth principle is motivation to learn. Adults have high motivation to learn when the learner can gain the new knowledge to help them to solve important problems in their life.

Brookfield (1995) also explored four major, unique and exclusive adult learning processes.

First, self-directed learning focuses on the process by which adults take control of their learning. Especially, they set up their learning goals, look for appropriate resources, decide on their learning styles and evaluate their progress. Then, critical reflection is a form and process, of learning how adults think contextually and critically. Third, experiential learning is such that adult teaching should be based on adults' experiences. Thus, those experiences could be a valuable resource. Finally, learning to learn is very crucial for adult development. When they become skilled at learning, adults have the ability of lifelong learning.

According to Lieb (1991), adult educators notice that learning happens in each individual as a continuous process throughout life. Regarding individual differences, it is natural for learners to be anxious or nervous when facing a new learning situation. Moreover, adults need high motivation for their learning since they have more responsibilities for their work and families. So, instructors need to give positive reinforcement at the proper time and present materials that are well structured in order to increase the chances of success. Drawing upon Speck's (1996) work, I list the following premises of adult learning theory that can be considered while designing professional development activities for online educators:

D Adults will commit to learning when the goals and objectives are considered realistic and important to them. Application in the 'real world' is important and relevant to the adult learners' personal and 
Making virtual learning interactive and meaningful: Implications of constructivism for adult students

professional needs.

$>$ Adults want to be the origin of their own learning and will resist learning activities they believe are an attack on their competence. Thus, professional development needs to give participants some control over the what, who, how, why, when, and where of their learning.

$>\quad$ Adult learners need to see that the professional development learning and their day-to-day activities are related and relevant.

$>\quad$ Adult learners need direct, concrete experiences in which they apply the learning in real work.

$>\quad$ Adult learning has ego involved. Professional development must be structured to provide support from peers and to reduce the fear of judgment during learning.

$>\quad$ Adults need to receive feedback on how they are doing and the results of their efforts. Opportunities must be built into professional development activities that allow the learner to practice the learning and receive structured, helpful feedback.

$>$ Adults need to participate in small-group activities during the learning to move them beyond understanding to application, analysis, synthesis, and evaluation. Small group activities provide an opportunity to share, reflect, and generalize their learning experiences.

$>$ Adult learners come to learning with a wide range of previous experiences, knowledge, self-direction, interests, and competencies. This diversity must be accommodated in the professional development planning.

$>\quad$ Transfer of learning for adults is not automatic and must be facilitated. Coaching and other kinds of follow-up support are needed to help adult learners transfer learning into daily practice so that it is sustained.

\section{Online technology in teaching and learning}

For many years technology has been effectively used in the field of education and in recent times it has become an indispensable tool of instruction. Technologies are considered as cognitive tools that help learners to elaborate on what they are thinking and to engage in meaningful learning (Jonassen, 2000). As well as the technology supports for effective instructional tool in traditional classroom settings, it has provided opportunities to offer education in virtual setting. As a result, from the last two decades the rapid development in the ICTs and the increasing use of the Internet worldwide has made it possible to provide online degrees. Such degree programs utilize the internet-based teaching that makes use of many forms of online technology.

Many commonly-used technologies can provide support for online learning, such as the Web, online discussion groups, online resources, and online courseware (Huang, 2002). The World Wide Web (Web) provides hypertext linked and hypermedia ability to facilitate educational instruction. Hypermedia and Web publishing are knowledge construction environments often incorporating information search engines for better understanding information and video for visualizing the range of ideas that students generate (Jonassen, 2000). The Web provides immense resources for adult learners. Through Web mechanisms, the learner can search actively and discover rich resource to solve problems or construct his or her own knowledge. Thus, the Web becomes a common tool for learner-centered or constructivist learning.

Video conferencing, email (voice mail), chat rooms, newsgroup or Bulletin Board System (BBS) via Internet can keep all learners of a learning group up to date to be formed and maintained by group teams online. Synchronous and asynchronous discussions focus the development of knowledge-building communities where participants share information in the pursuit of a meaning, and reflect on the knowledge that they have constructed, and the processes that they used (Jonassen, 2000). As Chen (1997) noted, many technologies can 
meet varied individual needs and each technology has its own particular instructional strengths. The newest technology product or the most expensive tool may not be the best one, but appropriate types of technology can really assist learners to improve their achievement. Sometimes, it may need appropriate selection and choice of a mix of delivery methods to meet the online learners' needs. Thus, the role of technology is the same as the instructor's: to be a facilitator in online learning.

McLoughlin et al. (2000) describe a number of tools and applications that can be used as online scaffolding mechanisms:

$>\quad$ Email for conversation, questioning and group dialogues

$>$ Threaded computer conferencing for collaborative problem solving, articulation and elaboration of views

$>$ Frequently-asked question lists that develop meta-cognition and self-direction

$>$ Hyperlinked resources to promote exploration, searching and resource selection and evaluation

$>$ Collaborative workspaces to provide multiple perspectives and social responsibility

$>$ Online chat to promote socio-cognitive dialogue, questioning and peer support.

\section{Implications of constructivism for adult learning in online setting}

\subsection{Interactive learning}

As described above, adult learning is effective in the 'real world' interactive environment. The constructivists such as Vygotsky and Dewey also contend that learning is less effective when learner is isolated from group. Though adults are independent learners, they better learn through dialogue and interaction. Therefore, I argue that the effectiveness of online learning tasks for adult learners depends on the way they generate interaction. As Barker (1994) has put it, interactivity is a "necessary and fundamental mechanism for knowledge acquisition" and Mesher (1999) claims interactivity is the "key to successful online learning." However, it is not quite so obvious exactly what sorts of interaction are most effective. Interaction can occur at different levels and in different ways. There are two sorts of interaction to consider; social and cognitive interaction. Obviously, online learning particularly for adult students will be most effective when these two approaches get integrated. Thus, if we were to create successful e-learning environments, it would seem that we would have to include means and mechanisms through which we can foster online social interactions that can enable learners to form strong relationships. Online communication tools such as newsgroups, discussion boards, chat and messaging programs can be used in many online learning courses.

Moreover, in advance level of interaction asynchronous discussions, debates and seminars can be used as effective tools. With increasing use of groupware, collaborative elements can be added to investigations and other activities. In addition to their uses in providing social interaction, they remain powerful tools for critique and for comparing understandings and points of view. Asynchronous discussion is often more thoughtful because it allows time for reflection, clarification or help (Mason \& Hart, 1997). Following the threads of such discussions and seminars often shows how the conceptual interactions between participants shape their ideas. In addition, traditional text can be intermingled with interactive exercises so that students can pace themselves while reading, yet still complete complementary interactive experiences alone or in cooperation with others. Moreover, interactivity can overcome the inherent limitations of textbook and lecture-based learning. The most effective learning is experiential and occurs, for example, when students go out into nature, or on ships, or to hospitals, or into outer space. As such travel is unrealistic; the use of web technology creates possibilities that are limited only by the imagination. 


\subsection{Experiential Learning}

Experiential learning is a concept central to both constructivism and andragogy. Experiential learning is composed of three components: (a) knowledge of concepts, facts, information, and experience; (b) prior knowledge applied to current, ongoing events; and (c) reflection with a thoughtful analysis and assessment of learners' activity that contributes to personal growth (Cercone, 2008). These concepts are crucial to experiential learning, and they should provide the basis of any adult learning experience. Brookfield (1995) agreed on the importance of experience for adult learning. According to Brookfield, the notion "that adult teaching should be grounded in adults' experiences, and that these experiences represent a valuable resource, is currently cited as crucial by adult educators of every conceivable ideological hue (para. 1)". Therefore, while devising online program for adult learners, it is essential to diagnose their prior experience and present need. According to their prior experience and present needs, then essential tasks are chosen so that they use prior knowledge and experience to perform the task.

Moreover, the constructivist approach of adult learning asserts that it is essential to see the link between what adults are learning and how it will apply to their lives. Since adults want to apply immediately their new knowledge in their live, it is essential to incorporate activities in online assignments that students can relate to, such as real situations or events. Adult also tends to self-reflect on the learning process, it is essential to provide a place in the course to discuss the process of learning online which may include thoughts on how they are managing in the online course. It is equally important to allow students to discuss options for their new roles, plan action strategies and exchange of knowledge and skills for effective and efficient online learning, and provide ways for learners to engage in metacognitive reflection. Students may benefit from the use of think logs, reflective journals, and group discussions within a cooperative learning setting.

\subsection{Self-directed Learning}

Self-directed learning, another central concept in both constructivism and adult education, suggests that the locus of control in learning lies with the adult learner, who may initiate learning with or without assistance from others (Lowry, 1989). Some learners need varying degrees of direction and support, while others are ready to be self-directed. Characteristics of self-directed learners include independence, willingness to take initiative, persistence in learning, self-discipline, self-confidence, and the desire to learn more. They are able to organize time, develop plans for completion, enjoy learning, and remain goal-oriented.

Self-directed learning has been confined to the informal learning situation until recently. Before the 1980s, learning was believed to occur only in a formal institution. Researchers now realize that self-directed learning is worthwhile as well as possible, and educators should encourage this type of learning in the formal classroom (Merriam \& Caffarella, 1999). Self-directed learning underlies Knowles' andragogy. The theory of andragogy acknowledges that as a person grows and matures his or her self-concept changes from that of a dependent personality toward that of a self-directed individual. Older methods of teaching did not foster self-directed learning and were primarily teacher-centered and passive. These methods of education may be difficult habits for older students to break, since they reflect the way in which they were taught. These students need to be guided as they progress toward self-direction to take more responsibility for their own learning. In terms of online learning, adults need scaffolding to be provided by the instructor. Scaffolding should promote self-reliance, and it should allow learners to perform activities they were unable to perform without this support. For this, it is essential to provide learner support after the initial training in the form of coaching, study teams, and opportunities to learn by watching his/her colleague's performance. It is also useful to coach using audio files or other methods to help in performance of the task.

\subsection{Collaborative learning}

Kaye (1992) defined collaborative learning as "the acquisition by individuals of knowledge, skills or 
attitudes occurring as the result of group interaction" with "individual learning as a result of the group process", (p. 4). Learning collaboratively implies peer exchange, a democratic interaction amongst equals who take on different roles (like facilitator, resource person and many others) according to the needs of the group and it involves synergy, assuming that the whole is greater than the individual parts. For success it required active and planned involvement within a context of shared goals, interests and commitments. As a medium for collaborative learning, computer conferencing is appropriate for adult learners because it provides the opportunity for "reflective and thoughtful analysis and review of earlier contributions" (Kaye, 1992, p. 17) rather than is the case in a face-to-face seminar where a contribution may be missed forever.

Social constructivists such as Vygotsky and Knowles also contend that the best learning occurs when students are actively engaged in the learning process and working in collaboration with other students to accomplish a shared goal. While constructivism focuses on personal experience as the foundation for learning new material, cooperative Learning utilizes not only the student's own experience to solidify knowledge, but also uses the experiences of others. Both theories emphasize the importance of interactivity with respect to the design and implementation of lesson plans. In cooperative learning, the focus moves from teacher-centered to student-centered education. Instead of sitting in a lecture or reading text, students are given a task or problem and are asked to identify a possible solution on their own and with the help of others. Rather than disseminating information directly, the teacher guides students to the source of the information they may require. In contrast to traditional teaching methods where students are perceived to be empty vessels awaiting the teachers' knowledge, Cooperative Learning theory recognizes the importance of the student's existing knowledge and puts that knowledge to work.

When cooperative learning is incorporated into the classroom, research suggests students learn with greater depth and complexity while enjoying the experience even more. Students who are asked to work together also tend to be less intimidated by the task and will work at the task with greater intensity for longer periods of time. In cooperative, online learning, adults can solve problems, answer questions, formulate questions of their own, discuss, explain, debate, write, or brainstorm during class. These students constantly analyze, puzzle over significance, search for explanations, and speculate about relations between the new experience and what they already know. Other active learning pedagogies include drama, role-playing and simulation, and peer teaching.

Cooperative Learning techniques developed for the classroom are easily adaptable to web-based learning. Further, the virtual interactivity achievable online can not only complement classroom-based learning, but it can offer a breadth and depth of interactivity unavailable in the classroom due to the inherent limitations of resources.

Online educators can use cooperative learning by

$>\quad$ Providing students opportunities to work alone and in cooperation with others;

$>\quad$ Making sure that students who work cooperatively also receive credit for their individual performance in the project;

$>\quad$ Using a variety of methods that appeal to different learning styles;

$>\quad$ Replacing static text with interactive pages; and

$>\quad$ Presenting the material in modules that use a variety of methods ranging from collaborative tasks to individual tasks.

\subsection{Authentic learning}

Adult learning and constructivism both contend that learning-by-doing or solving real-world problems is the most effective way to learn. Authentic learning always encourages students to expose themselves to that 
Making virtual learning interactive and meaningful: Implications of constructivism for adult students

environment, allowing them to have a real experience by the process of learning-by-doing. This is effective more for adult learners as they prefer always to learn through practical experience. In online setting, the Internet and a variety of emerging communication, visualization, and simulation technologies now make it possible to offer students authentic learning experiences ranging from experimentation to real-world problem solving. Significantly, educational researchers are coming to the conclusion that "the value of authentic activity is not constrained to learning in real-life locations and practice, but that the benefits of authentic activity can be realized through careful design of web-based learning environments" (Herrington et al., 2002).

There are various ways to provide authentic learning environment that is suitable for adult learners. With borrowing ideas from the reviewed literatures, the researcher proposes the following strategies effective for enhancing the authentic learning for adults in the online environment:

$>\quad$ Simulation-based learning by creating online environment that uses role-playing to immerse students in the complexities of authentic decision making, helping them develop the communication, collaboration, and leadership skills they will need to be successful practitioners in their fields.

$>\quad$ Student-created media by engaging adults to develop 3D model or creating diagram of the object, ideas or process they study.

$>\quad$ Inquiry-based learning by designing web-based program to engaging students to investigate the problem providing students with the scaffolding they need at every stage of their development as professionals.

$>\quad$ Peer-based evaluation by training students to evaluate their fellow's learning by using proper online software.

\section{Conclusion}

Two major conclusions can be drawn from the above discussions. First, interactive and meaningful learning has its roots in constructivism and online technology provides various interactive strategies for active learning. Next, adults have special characteristics and learning needs than those of younger learners. Therefore, same scaffolding mechanism and learning opportunities may not be appropriate for both groups of learners. Reflecting on the needs and characteristics of adult learners, this article has discussed the five types of learning strategies rooted in constructivism which are particularly useful in the online learning environment. Considering these five possibilities of learning online educators can find multiple ways of addressing the learning needs of adult learners and therefore can provide them with a better experience and joy of learning.

Online learning will continue to grow in importance for adult learners. The challenge for educators is to learn how to provide a positive "social" environment using an electronic medium. Instructional programs will continue to change as new technologies grow. Instructors therefore will need to adapt, change, and continue to learn about how this "electronic" environment can be used to foster a social atmosphere, and they will need to recognize their role as change agents. 


\section{References:}

Barker, P. (1994). Designing interactive learning. In T. de Jong \& L. Sarti (Eds.), Design and production of multimedia and simulation-based learning material (pp. 1 -30). Dordrecht: Kluwer Academic. http://dx.doi.org/10.1007/978-94-011-0942-0_1

Brookfield, S. (1995). Adult learning: An overview. In A. Tuinjman (Ed.) International Encyclopedia of Education (pp. 375 - 380). Oxford: Pergamum Press.

Brooks, J. G., \& Brooks, M. G. (1993). In search of understanding: The case for constructivist classrooms. Alexandria, VA: Association of Supervision and Curriculum Development.

Bryceson, K. (2007). The online learning environment: A new model using social constructivism and a concept of 'Ba' as theoretical framework. Learning Environment Research, 10, 189-206. http://dx.doi.org/10.1007/s10984-007-9028-x

Cercone, K. (2008). Characteristics of adult learners with implications for online learning design. AACE Journal, 16(2), 137-159.

Chen, L. L. (1997). Distance delivery systems in terms of pedagogical considerations: A re-evaluation. Educational Technology, 37, 34-37

Harmon, S. W., \& Jones, M. C. (1999). The five levels of Web use in education: Factors to consider in planning online courses. Educational Technology, 39(6), 28-31.

Huang, H. (2002). Towards constructivism for adult learners in online learning environments. British Journal of Educational Technology, 33(1), 27-37. http://dx.doi.org/10.1111/1467-8535.00236

Herrington, J., Reeves, T., Oliver R., \& Woo, Y. (2002). Designing authentic activities for Web-based courses. In G. Richards (Ed.), Proceedings of World Conference on E-Learning in Corporate, Government, Healthcare, and Higher Education 2001 (pp. 18-27). Chesapeake, VA: AACE.

Jonassen, D. H. (2000). Transforming learning with technology: Beyond modernism and postmodernism or whoever controls the technology creates the reality. Educational Technology, 40(2), 21-25.

Kaye, A. R. (1992). Learning together apart. In A. R. Kaye (Ed.), Collaborative learning through computer conferencing (pp. 1- 24), London: Springer-Verlag. http://dx.doi.org/10.1007/978-3-642-77684-7_1

Ke, F., \& Xie, K. (2009) Toward deep learning for adult students in online education. The Internet and Higher Education, 12(3/4), 136-145. http://dx.doi.org/10.1016/j.iheduc.2009.08.001

Knowles, M. S. (1980). The modern practice of adult education. Andragogy versus pedagogy. Englewood Cliffs: Prentice Hall/Cambridge.

Knowles M. S., Holton, E. F., \& Swanson R. A. (1998). The adult learner (5th ed.) Houston, TX: Gulf Publishing.

Lieb, S. (1991). Principles of adult learning. Phoenix, AZ: Vision, South Mountain Community College.

Lowry, C. M. (1989). Supporting and facilitating self-directed learning. (ERIC Document Reproduction Service No. ED312 457).

Mason, J., \& Hart, G. (1997). Effective use of asynchronous virtual learning communities. Sydney: University of Sydney.

McLoughlin, C., Winnips, K., \& Oliver, R. (2000). Supporting constructivist learning through Learner Support On-line. In J. Bourdeau \& R. Heller (Eds.), Proceedings of world conference on educational multimedia, hypermedia and telecommunications 2000 (pp. 674-680). Chesapeake, VA: Association for the Advancement of Computing in Education (AACE).

Merriam, S. B., \& Caffarella, R.S. (1999). Learning in adulthood (2nd ed.), San Francisco, CA: Jossey-Bass.

Mesher, D. (1999). Designing interactivities for Internet learning. Syllabus, 12(7), 16-30.

Moore, M. G., \& Kearsley, G. (1996). Distance education a systems view. Belmont, CA: Wadsworth.

Petraglia, J. (1998). The real world on a short leash: The (mis)application of constructivism to the design of educational technology, Educational Technology Research and Development, 46(3), 53-65. http://dx.doi.org/10.1007/BF02299761 
Making virtual learning interactive and meaningful: Implications of constructivism for adult students

Piaget, J. (1977). The development of thought: equilibrium of cognitive structures. New York: Viking.

Resnick, L., \& Collins, A (1996). Cognition and learning. In E. De Corte \& F. E. Weinert, International encyclopedia of developmental and instructional psychology (pp. 377 - 381). New York, NY: Elsevier Science.

Rossner-Merrill, V., Parker, D., Mamchur, C., \& Chu, S. (1998). Using constructivist instructional design featured in two online courses: Notes from the field, Educational Media International, 35(4), 282-288. http://dx.doi.org/10.1080/0952398980350412

Rovai, A. P. (2004). A constructivist approach to online college learning, Internet and Higher Education, 7(2), 79-93. http://dx.doi.org/10.1016/j.iheduc.2003.10.002

McLoughlin, C. (2002). Learner support in distance and networked learning environments: ten dimensions for successful design. Distance Education, 32(2), 149-162. http://dx.doi.org/10.1080/0158791022000009178

Speck, M. (1996). Best practice in professional development for sustained educational change. ERS Spectrum, 14(2), 33-41.

Vygotsky, L. S. (1978). Mind in society: The development of higher psychological processes. Cambridge, MA: Harvard University Press. 
Khanal, P. 